APPENDIX (continued from page 573)

ZUCKERMAN's SENSATION-SEEKING SCALE

(FRENCH ABBREVIATED FORM)

28. A. I prefer friends who are excitingly unpredictable.

B. I prefer friends who are reliable and predictable.

29. A. I like to dive off the high board.

B. I don't like the feelings I get standing on the high board (or I don't go near it at all).

30. A. I would not like to learn to fly an airplane.

B. I would like to learn to fly an airplane.

31. A. I get bored seeing the same old faces.

B. I like the comfortable familiarity of everyday friends.

32. A. I would like to take off on a trip with no pre-planned or definite routes, or timetable.

B. When I go on a trip I like to plan my route and timetable fairly carefully.

33. A. There is altogether too much portrayal of sex in movies.

B. I enjoy watching many of the sexy scenes in movies.

34. A. I dislike the sensations one gets when flying.

B. I enjoy many of the rides in amusement parks.

35. A. I am not interested in experience for its own sake.

B. I like to have new and exciting experiences and sensations even if they are a little frightening, unconventional, or illegal.

36. A. I feel best after taking a couple of drinks.

B. Something is wrong with people who need liquor to feel good.

37. A. I dislike people who do or say things just to shock or upset others.

B. When you can predict almost everything a person will do and say he or she must be a bore.

38. A. I enjoy looking at home movies or travel slides.

B. Looking at someone's home movies or travel slides bores me tremendously.

39. A. I would like to go scuba diving.

B. I prefer the surface of water to the depths.

40. A. I like wild, uninhibited parties.

B. I prefer quiet parties with good conversation.

Factors composition

\title{
GAO Issues Report on Reuse of Single-Use Medical Devices
}

Gina Pugliese, RN, MS

Martin S. Favero, PhD

According to a US General Accounting Office (GAO) report released on June 20 , the FDA's proposed reprocessing regulations for hospitals and third-party reprocessors may be difficult to implement and may have limited impact on public health. The report also warns that more oversight is needed to ensure the safety of reprocessing of single-use devices (SUDs).

Thirteen third-party reprocessors have been identified in the United States, and approximately $30 \%$ of hospitals surveyed by the GAO reported reuse of an SUD, with a third of these using third-party reprocessing companies. The report notes that many healthcare workers question the single-use labels, because the FDA does not require manufacturers to support the single-use designation. Although the CDC has had few reports of adverse outcomes associated with reuse of SUDs, not all SUDs are appropriate for reuse, and cleaning and sterilization procedures are not always followed correctly. The report notes that sur- veillance systems and voluntary reporting of adverse events may be incomplete. The GAO believes that compliance with the proposed new rules, particularly the newly required premarket approval applications, may prove to be difficult for hospitals. This will likely result in hospitals turning to thirdparty reprocessors in the future.

FROM: Government Accounting Office. Single-use medical devices: little available evidence of harm from reuse, but oversight warranted. GAO June $10,2000$. http://www.gao.gov/new.items/he00123. pdf. 